\title{
An Analysis on the Semantic Difference of the Restrictive and Non-restrictive Attributive Clause \\ Yao Zhao ${ }^{1}$, Songlin Yang ${ }^{1,}{ }^{*}$, Chang Liu ${ }^{1}$ \\ ${ }^{1}$ Foreign Languages College, Beihua University, Jilin, Jilin Province, China \\ ${ }^{*}$ Corresponding author
}

\begin{abstract}
Keywords: semantic relation, attributive clauses, restrictive and non-restrictive
\end{abstract}
\begin{abstract}
The attributive clause is important in daily communication and teaching and studying in schools. The thesis is to analyze the different meaning of the restrictive and non-restrictive attributive clauses based on the semantic triangle in order to enhance the exact comprehension and teaching and studying in high schools.
\end{abstract}

\section{Introduction}

As one of the basic grammar items, the attributive clause is not more frequently used in spoken and written styles, but also is importantly instructed in senior high schools as the foreign language. The semantic meaning of the attributive clause is complex and intriguing. The thesis is to analyze the different meaning of the attributive clause, especially the restrictive and non-restrictive clauses based on the semiotic triangle.

\section{Literature review}

The attributive clause. The attributive clause is a dependent clause which taking the place of an adjective clause or phrase in the complex sentence connected by the relative pronoun or adverb [1].

It is generally classified into the restrictive and non-restrictive attributive clause. The restrictive clause has a close relation with its antecedent and its function is restrictive and modified. The non-restrictive attributive clause has a less close relation with the antecedent separated with a comma and is used to narrate, describe or explain the whole idea expressed in a preceding clause.

The semantic triangle. The semantic triangle, as the basic theory of semantics is raised by Leech. [2]

Ferdinand de Saussure points out that the linguistic sign consists of a signifier and a signified, namely a sound and a concept. [3]

In this Figure, the symbol or form refers to linguistic elements (words, phrases), the referent refers to the things in the real world, and thought or reference refers to "concept".

Its main idea is that the word or sentence, as a symbol, symbolizes the thought or reference which refers to an object, that is, a referent. The symbol stands for the object and its relations is arbitrary and conventional.

According to Leech, words, either written or spoken, are linguistic symbols, which have meaning only when they have acquired reference. Reference is the relationship between language and the world. By means of reference, a speaker indicates which things in the world (including persons) are 
being talked about. Only when a connection has been established between the linguistic sign and a referent (an object, a phenomenon, a person) does the sign become meaningful. This connection is arbitrary and conventional. [4] According to the figure, we know that whenever there is a word, there is a concept, then the meaning is based on the meaning of a word.

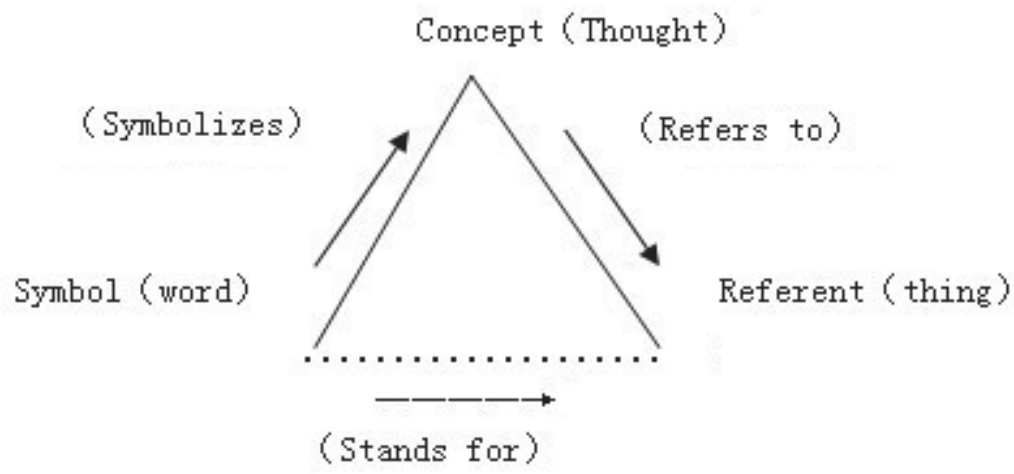

\section{Analysis on the Semantic Difference of the restrictive and non-restrictive Attributive Clause}

Generally speaking, most foreign language learners consider that the difference in meaning between the restrictive and non-restrictive attributive clause is not too serious. The non-restrictive attributive clause is separated by an extra comma, whose meaning is loose and may be there or not. The antecedent (symbol) in the restrictive and non-restrictive attributive clause symbolizes the same referent (object), which gets the certain reference (concept) between them. However both of them have complete difference in meaning. The chapter is to analyze the different meaning of the restrictive and non-restrictive attributive clause based on the semantic triangle.

For example:

The students who wanted to play volleyball were disappointed when it was windy.

The students, who wanted to play volleyball, were disappointed when it was windy.

According to the grammar, the attributive clauses, which in the above two sentences have no difference in meaning, own the same function to modify the antecedent. The sole difference in the structure is that the non-restrictive clause in the (2) is looser compared with that in the (1) and can be deleted without any loss in sense.

However it is required to be analyzed more carefully and comprehensively. The function of the restrictive attributive clause is restrictive and modified. In the (1), the clause who wanted to play volleyball is used to modify and restrict the sense of the antecedent the students. It restricts and modifies the students whose sense refers that not all of them were disappointed due to the wind, that is, some were disappointed and some not. In other words, its sense is that among all the students some want to play volleyball and disappointed with the wind. It can also be inferred that some of the students did not care for the wind.

Based on the semantic triangle, the symbol the students symbolizes the referent a part of the students who were disappointed by the rain. The reference is between the students and a part of the students who were disappointed by the rain. It implies that the word students stands for the object not all the students.

Concerning the sentence (2), the function of the nonrestrictive attributive clause is to narrate, 
describe or explain the whole idea expressed in a preceding clause. In the (2), the clause who wanted to play volleyball, separated by a comma, is used to narrate, describe and explain the sense of the antecedent the students. It narrates the students as a whole, that all of them wanted to play volleyball and were disappointed due to the wind. In another word, its sense is that all the students want to play volleyball and disappointed with the wind.

Based on the semantic triangle, the symbol the students symbolizes the referent all of the students wanted to play volleyball and were disappointed by the rain. The reference is between the students as a whole and all of them. It implies that the word students stands for the object all of the students wanted to play volleyball and were disappointed by the rain.

To sum up, even the antecedents are same in (1) and (2), the function of various attributive clauses constrains the sense of the antecedent and cause its different sense. From the perspective of semantic triangle, the symbol is same, the referent is different and the references are totally different. The relation can be shown by the following picture.
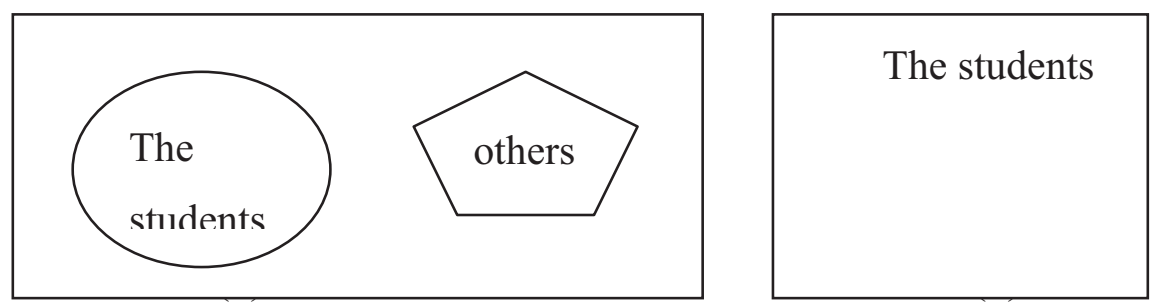

For example:

The visitors who heard of the flood took another road.

The visitors, who heard of the flood, took another road.

The attributive clause in (3)who heard of the flood restricts and modifies the scope of the antecedent visitors. It restricts the visitors which refers to only those visitors that knew the flood, that is, some knew and some did not. In other words, its sense is that among all the visitors some heard of the flood and took another decision. It can also be inferred that some of all the visitors did not know the flood and kept the old road.

Based on the semantic triangle, the symbol the visitors symbolizes the referent a part of the visitors who heard of the flood. The reference is between the visitors and a part of the visitors who heard of the flood. It implies that the word visitors stands for the object not all the visitors.

Concerning the sentence (4), the function of the nonrestrictive attributive clause has no any restriction. In the (4), the clause who heard of the flood narrates and explains the sense of the antecedent the visitors. It narrates the visitors as a whole, that all the visitors heard of the flood and took another road.

Based on the semantic triangle, the symbol the visitors symbolizes the referent all of the visitor heard the flood and took another road. The reference is between the visitors as a whole and all of them. It implies that the word visitors stands for the object all of the visitors heard the flood and took another road.

For example:

The liquor which has been stored in the cellar has better taste.

The liquor, which has been stored in the cellar, has better taste.

The restrictive attributive clause in (5) which has been stored in the cellar modifies the category of the antecedent the liquor. It modifies the liquor which refers to only the liquor that has been 
stored in the cellar, that is, the liquor in the cellar is good and other stored in some places else does not. Namely, its sense is that among all the liquor only that stored in the cellar has better taste. It implies that maybe some liquor not being stored in the cellar does not taste so good.

Based on the semantic triangle, the symbol the liquor symbolizes the referent that has been stored in the cellar. The reference is between the liquor and that liquor in the cellar. It implies that the word liquor stands for the object that liquor in the cellar.

Concerning the sentence (6), the function of the nonrestrictive attributive clause describes the status of all the liquor in the cellar. In the (6), the clause which has been stored in the cellar describes the sense of the antecedent the liquor. Whether there is any liquor else or not, it is not taken into consideration in the sentence.

Based on the semantic triangle, the symbol the liquor symbolizes the referent which has been stored in the cellar. The reference is between the liquor as a whole and all of them. It implies that the word liquor stands for the object all of the liquor in the cellar.

\section{Conclusion}

To sum up, the semantic difference of the restrictive and non-restrictive attributive clause should be noticed in teaching and studying. The semantic triangle theory is effective to analyze the difference.

First, the grammar function clearly states the difference in both attributive clauses. The restrictive clause owns closer relation with its antecedent and functions restriction and modification. The non-restrictive attributive clause has a looser relation with the antecedent separated with a comma and has function to narrate, describe or explain the whole idea expressed in a preceding clause. The different grammar functions indicate the sense of the antecedent clearly which is required to consider thoroughly in understanding the meaning. That is necessary to take into consideration while readers comprehending the sentences. The antecedent in the restrictive clause refers to a part of the whole and implies the condition of the others. On the contrary, that of the non-restrictive attributive clause refers to the total with the same status and do not care for the others.

Secondly, the semantic theory is good in distinguishing the different reference set up between the symbol and referent. Through analysis, the different meaning is apparently shown by the references which help readers comprehend them. The same symbol in both the restrictive and non-restrictive attributive clauses designates the different referents with different reference by different concept or thought. That is, the same word (antecedent) symbolizes different thought which refers to different object in the world.

At last, the word which gets its exact meaning depends on the context. The context includes the linguistic and non-linguistic context. The sense of the antecedent of the attributive clauses is required to understand from the two contexts except the function.

\section{References}

[1] Zhang Daozhen, An Introduction to Grammar, Foreign Language Studying and Teaching, Beijing, 2005. 
[2] G.Leech, Semantics: The Study of Meaning, second ed., Penguin, Harmondsworth, 1974.

[3] Lin Chengzhang, An Introduction to English Lexicology, Wuhan, 2009.

[4] Lyons. John, Semantics, Cambridge University Press. Cambridge, 1981. 